\title{
Commentary: The elephant in the room: Routine arch repair for acute dissection?
}

\author{
Ali Hage, MD, MPH, ${ }^{\mathrm{a}}$ Mark D. Peterson, MD, $\mathrm{PhD},{ }^{\mathrm{b}}$ \\ Maral Ouzounian, MD, $\mathrm{PhD}{ }^{\mathrm{b}}$ \\ Ismail El-Hamamsy, $\mathrm{MD}, \mathrm{PhD},{ }^{\mathrm{c}}$ \\ Francois Dagenais, MD, ${ }^{\mathrm{d}}$ and \\ Michael W. A. Chu, MD, MEd, ${ }^{\text {a }}$ on behalf of the \\ Canadian Thoracic Aortic Collaborative (CTAC)
}

There has been a growing trend for more liberal use, and in some centers routine use, of total aortic arch replacement and elephant trunk repair techniques in patients presenting with acute type A aortic dissection (ATAAD). While the classic elephant trunk may help with hemostasis in complex arch tears, the frozen elephant trunk (FET) has gained popularity in ATAAD because of the ability to extend repairs into the descending aorta and potentially improve early distal malperfusion and late distal aortic remodeling and its sequelae. In centers of excellence, an FET repair can be performed with good outcomes, but increased risk of spinal cord injury remains paramount, particularly when deployed beyond T8. ${ }^{1,2}$ Other complications of FET include endoleaks, stent graftinduced new entry tears, endoluminal thrombus formation with subsequent embolism, and prosthetic graft infection.

From ${ }^{\mathrm{a}}$ Western University, London; and ${ }^{\mathrm{b}}$ University of Toronto, Toronto, Ontario, Canada; ${ }^{c}$ Mount Sinai Hospital and Icahn School of Medicine at Mount Sinai, New York, New York; and ${ }^{\mathrm{d}}$ Laval University, Quebec City, Quebec, Canada.

Disclosures: M.W.A.C. has received Speaker's honoraria from Medtronic, Edwards Lifesciences, Terumo Aortic, and CryoLife. M.D.P. has consulted for Medtronic, Edwards Lifesciences, and LivaNova. M.O. has received speaker's honoraria from Medtronic, Edwards Lifesciences, and CryoLife. All other authors reported no conflicts of interest.

The Journal policy requires editors and reviewers to disclose conflicts of interest and to decline handling or reviewing manuscripts for which they may have a conflict of interest. The editors and reviewers of this article have no conflicts of interest.

Received for publication Dec 8, 2020; revisions received Dec 8, 2020; accepted for publication Dec 18, 2020; available ahead of print Dec 28, 2020.

Address for reprints: Michael W. A. Chu, MD, MEd, B6-106 University Hospital, London Health Sciences Centre, 339 Windermere Rd, London, Ontario, Canada N6A 5A5 (E-mail: Michael.Chu@1hsc.on.ca).

JTCVS Techniques 2021;6:50-1

2666-2507

Copyright (C) 2020 The Authors. Published by Elsevier Inc. on behalf of The American Association for Thoracic Surgery. This is an open access article under the CC BY-NCND license (http://creativecommons.org/licenses/by-nc-nd/4.0/).

https://doi.org/10.1016/j.xjtc.2020.12.026

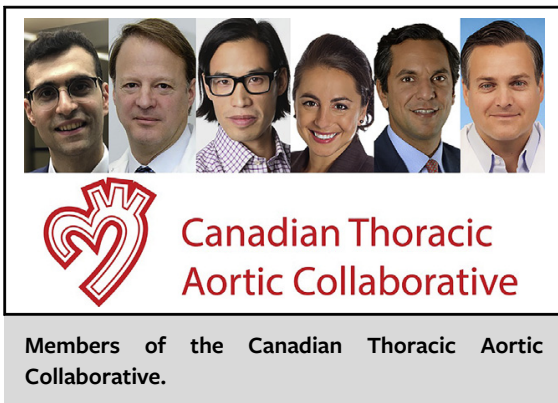

CENTRAL MESSAGE

Performing an elephant trunk repair for acute type $A$ aortic dissection may improve late outcomes, but one must carefully weigh the potential risks versus the benefits.

Minegishi and colleagues ${ }^{3}$ describe an interesting case of a 72-year-old-woman with an ATAAD undergoing emergency total aortic arch replacement with FET complicated by recurrent early bacterial and eventually fungal prosthetic graft infection involving the repeatedly replaced xenopericardial roll elephant trunk. The authors should be congratulated for their Herculean management of the impossibly difficult problem of recurrent prosthetic graft infection. Although all the details were likely challenging to include in this short report, it remains unclear the need for repeated elephant trunk reimplantation with each successive reoperation despite the resolution on computed tomography of any distal residual aortic dissection with complete true lumen expansion and false lumen collapse. In the absence of any residual distal dissection or arch aneurysm, one must weigh the utility of an added elephant trunk repair against the potential risks, albeit rare. In this case, it is likely that recurrent graft infection would have ensued regardless; however, one could only speculate whether the fungal ball-obstructed elephant trunk could have been avoided altogether by simply reconstructing the distal zone 3 anastomosis without the repeated xenopericardial roll elephant trunk.

In summary, the elephant trunk repair technique, both conventional and frozen, has an important role in management of ATAAD, offering many short- and long-term advantages. However, desire for more aggressive distal remodeling should be carefully weighed against the increased risk of cerebrovascular and spinal cord complications associated with a total arch FET procedure (as 
opposed to a standard hemiarch repair), particularly in centers with lower volumes of aortic surgery. Furthermore, there may be unintended consequences, as highlighted in this challenging case of recurrent prosthetic infection. The authors have bravely managed their patient to this point, although with a Candida albicans infection and residual proximal aortic graft material, this patient is likely to have a lifelong battle with this rare, life-threatening elephant trunk complication.

\section{References}

1. Ouzounian M, Hage A, Chung J, Stevens LM, El-Hamamsy I, Chauvette V, et al; Canadian Thoracic Collaborative (CTAC) Investigators. Hybrid arch frozen elephant trunk repair: evidence from the Canadian Thoracic Aortic Collaborative. Ann Cardiothorac Surg. 2020;9:189-96.

2. Hanif H, Dubois L, Ouzounian M, Peterson MD, El-Hamamsy I, Dagenais F, et al; Canadian Thoracic Collaborative (CTAC) Investigators. Aortic arch reconstructive surgery with conventional techniques vs frozen elephant trunk: a systematic review and meta-analysis. Can J Cardiol. 2018;34:262-73.

3. Minegishi S, Inaba Y, Endo H, Kubota H. A large vegetation on a xenopericardial roll elephant trunk graft. J Thorac Cardiovasc Surg Tech. 2021;6:46-9. 